\title{
Resection of a Petroclival Meningioma via the Endoscope-Assisted Retrosigmoid Approach: 2-D Operative Video
}

\author{
Stefan Lieber ${ }^{1,2}$ Rocio Evangelista-Zamora ${ }^{1}$ Florian H. Ebner ${ }^{1}$ Marcos Tatagiba ${ }^{1}$ \\ ${ }^{1}$ Department of Neurological Surgery, Eberhard-Karls University, \\ University Hospital Tübingen, Tübingen, Germany \\ 2 Department of Neurological Surgery, Microsurgical Neuroanatomy Lab, \\ University of Pittsburgh, Pittsburgh, Pennsylvania, United States \\ Address for correspondence Stefan Lieber, MD, Department of
Neurological Surgery, Eberhard-Karls University, Hoppe-Seyler-Strasse
3, D-72076 Tübingen, Germany
(e-mail: Stefan.Lieber@uclmail.net).
} J Neurol Surg B 2018;79(suppl S5):S395-S396.

Abstract

Keywords
- petroclival
meningioma
- retrosigmoid
approach
- suprameatal tubercle
- endoscope-assisted
approach

We present a case of a petroclival meningioma that was resected through an endoscope-assisted retrosigmoid approach via corridors above and below the facialvestibulocochlear nerve complex. The patient is a 61-year-old female with complaints of left-sided hypesthesia and neuralgia of the infraorbital and zygomatic region, intermittent periorbital myokymia, and a slight facial palsy (HB II). This 2D video demonstrates the operative technique, anatomical and surgical nuances of the skull base approach and microdissection of the tumor from the critical neurovascular structures. A gross total resection was achieved. The patient's facial and trigeminal symptoms resolved completely within a few weeks. At 2 year follow up there was no indication of residual or recurrence.

In summary, the retrosigmoid approach with endoscopic assistance is an important and powerful tool in the armamentarium for the microsurgical management of meningiomas of the lateroventral skullbase of the posterior fossa.

The link to the video can be found at: https://youtu.be/Px4XIRDoALc.

\section{Disclosures}

None; the authors have no personal, institutional, or financial interest in any of the materials, drugs, or devices described in this article.

Conflict of Interest

None.

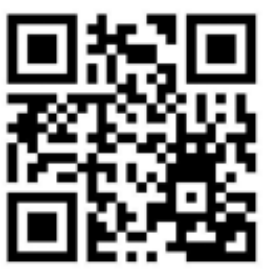

received

June 5,2018

accepted

August 11, 2018

published online

October 1, 2018 www.thieme.com/skullbasevideos

www.thieme.com/jnlsbvideos
License terms

DOI https://doi.org/ 10.1055/s-0038-1669984. ISSN 2193-6331. (c) 2018 Georg Thieme Verlag KG Stuttgart · New York 

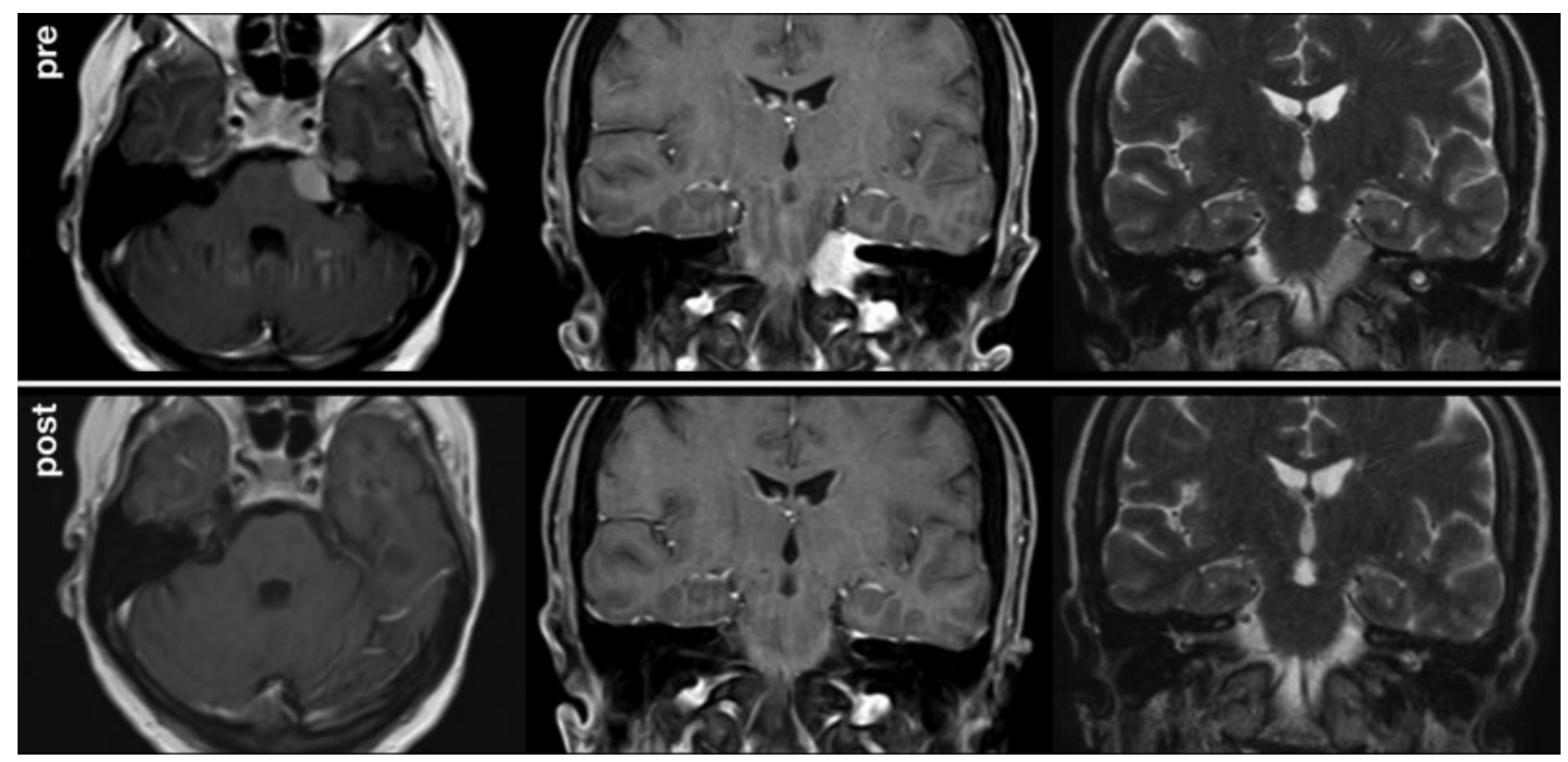

Fig. 1 Pre and postoperative MRI of the left-sided petroclival meningioma, extending from the pontomedullary junction to the tentorial incisura.
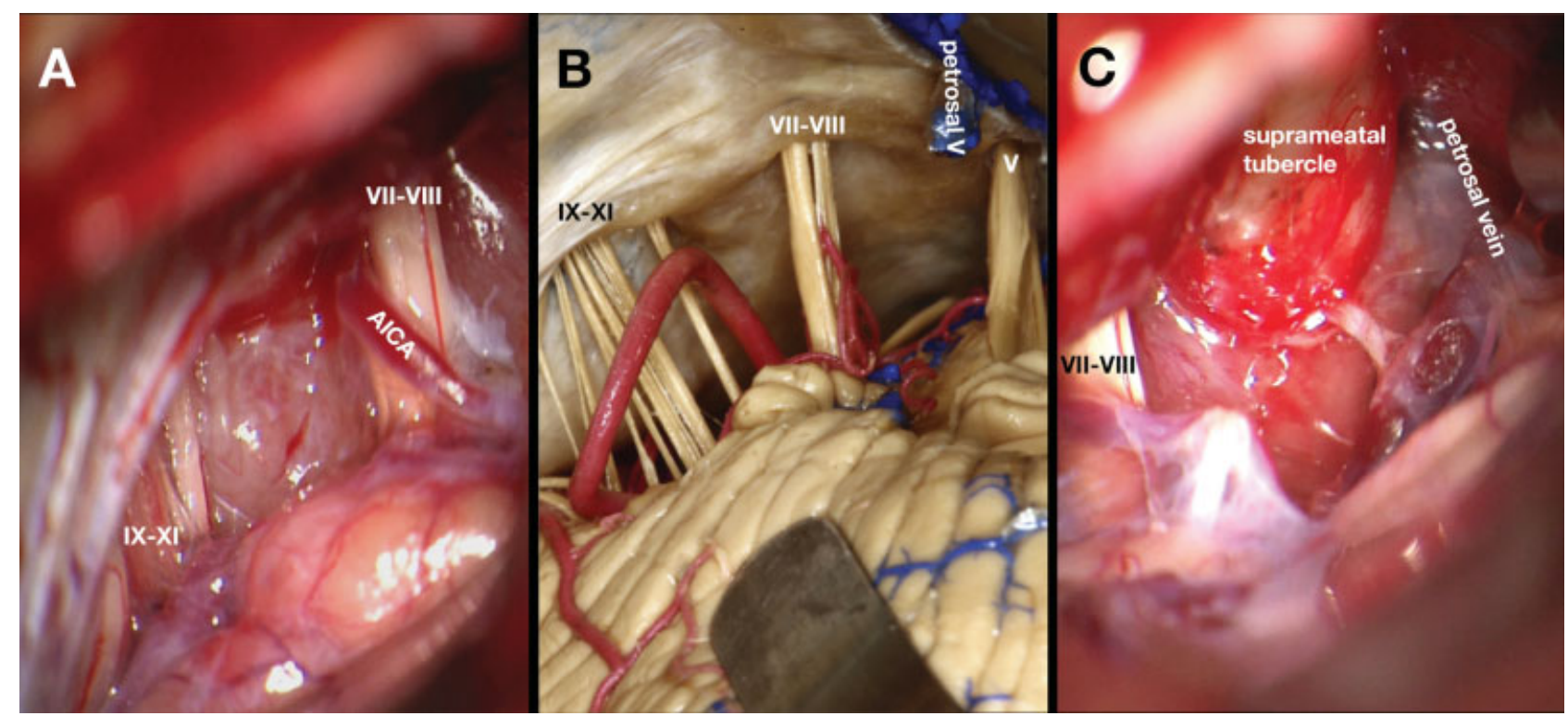

Fig. 2 Illustration of the corridors used for microsurgical resection of this petroclival meningioma: (A) the corridor between the lower cranial nerves and the facial-vestibulocochlear nerve complex, (C) the corridor between the facial-vestibulocochlear nerve complex and the trigeminal nerve, (B) dissection in a human specimen for anatomical correlation. 